RELATO DE
EXPERIÊNCIA

Recebido em:

25/02/2015

Aceito em:

$15 / 12 / 2015$

\title{
Processo dialógico entre bibliotecários e usuários: reflexão em torno da utilização dos dispositivos de comunicação da web social
}

Dialogic process between users and librarians: reflection around in the use of social web communication devices

Raquel do Rosário SANTOS

Doutoranda em Ciência da Informação UFPB - quelrosario@gmail.com

\section{Henriette Ferreira GOMES}

Professora do Instituto de Ciência da Informação e PPGCI UFBA henriettefgomes@gmail.com

Emeida Nóbrega DUARTE

Professora do Departamento de Ciência da Informação UFPB - emeide@hotmail.com

\section{Resumo}

A utilização dos dispositivos de comunicação da web social pelas bibliotecas universitárias públicas brasileiras, como um recurso que pode potencializar a mediação da informação por meio da interação entre usuários e bibliotecários é o tema deste trabalho, que teve por objetivo identificar e analisar como as bibliotecas das universidades federais e estaduais têm explorado os recursos de comunicação nos websites para ampliar suas ações voltadas à mediação para o acesso e uso da informação. A técnica da observação direta e intensiva dos websites foi adotada para análise do uso dos dispositivos de comunicação da web social e se o mesmo tem ampliado a mediação realizada pelas bibliotecas centrais e/ou sistemas de bibliotecas das IES Estaduais e IFES para o acesso e uso da informação. Constatou-se neste trabalho que, ainda são poucos os casos de bibliotecas que, além de disponibilizarem conteúdos relevantes para auxiliar os usuários no acesso e uso da informação, bem como conteúdos sobre a biblioteca, também vêm explorando os dispositivos para favorecer a participação ativa dos usuários na troca de informações, debates, comentários e manifestação de sugestões. Assim, concluiu-se que, embora em menor quantidade e ainda necessitando de maior planejamento nas ações, há uma parcela das bibliotecas centrais e/ou sistemas de bibliotecas das IES Estaduais e das IFES analisadas que têm procurado avançar no modo de aproximação e de relacionamento com os usuários, como também vêm apresentando uma nova conduta de comunicação por parte dos bibliotecários que se mostraram mais acolhedores e amigáveis na interlocução com os usuários por meio dos dispositivos de comunicação da web social.

Palavras-chave: Bibliotecas universitárias. Mediação da informação - Bibliotecas universitárias. Web social - Bibliotecas universitárias.

v. 21, n. 45,2016 


\begin{abstract}
The use of the communication devices of the social web by the Brazilian public university libraries as a resource that can enhance the mediation of information through the interaction between users and librarians is the subject of this work. This research aimed to identify and analyze how the libraries of the federal and state universities have explored the communication resources in the websites to enlarge their actions turned to the mediation for the access and use of information. The technique of direct and intensive observation of the websites was adopted for the analysis of the use the communication devices of the social web and whether it has expanded the mediation conducted by the central libraries and / or library systems of the state and federal universities to the access and use of information. It was noticed in this work that, there are still few libraries that, besides to make available relevant contents to help the users in the access and use of information as well as the contents about the library, have also been exploring the devices to encourage the active participation of the users in the exchange of information, discussions, comments and suggestions. Thus, it was concluded that, although in a smaller quantity and still requiring more planning in the actions, there is a parcel of the central libraries and / or library systems of the state and federal universities analyzed that have sought to promote the way of approaching and relationship with the users, as they are also presenting a new communication conduct on the part of the librarians who were more welcoming and friendly in the dialogue with the users through the communication devices of the social web.
\end{abstract}

Keywords: University libraries. Mediation of information - University libraries. Social Web University libraries.

\title{
1 INTRODUÇÃo
}

A mediação, por meio das atividades desenvolvidas pelos bibliotecários, é um elemento essencial para favorecer o processo de construção de sentido e apropriação da informação. 0 mediador possui um papel fundamental no processo de desenvolvimento dos sujeitos, uma vez que esse articula a aproximação entre o sujeito e o objeto, auxiliando o crescimento intrapessoal, como também atuando na aproximação entre os sujeitos, potencializando as relações sociais.

O espaço virtual vem demonstrando ser um importante dispositivo para o processo de transmissão de informações, um veículo rápido e acessível para o provimento de respostas aos usuários, assim se apresentando como um importante aliado para a construção de redes de conhecimento a partir do ambiente da biblioteca. A utilização da web e os seus dispositivos de comunicação poderá também fomentar o desenvolvimento de atividades de mediação da informação para além dos ambientes físicos das bibliotecas, impulsionando a promoção de novas formas de acesso à informação no ambiente virtual.

Assim, justificou-se a realização de uma pesquisa realizada no curso de Mestrado em Ciência da Informação, cujo problema consistiu em investigar se e como as bibliotecas das universidades públicas federais e estaduais vêm utilizando os dispositivos de comunicação na web, a exemplo do "fale conosco", das listas e grupos de discussão, blogs, twitters, dentre outros, para manter uma comunicação direta com seus usuários intensificando o processo de interlocução que favorece a mediação da informação. A resposta a este problema de pesquisa teve como objetivo geral analisar como as bibliotecas universitárias federais e estaduais têm 
explorado os dispositivos de comunicação nos websites para ampliar suas ações voltadas à mediação para o acesso e uso da informação.

Os resultados da pesquisa apontaram que ainda são poucos os casos de bibliotecas que além de disponibilizar conteúdos relevantes para auxiliálos no acesso e uso da informação, bem como conteúdos sobre a biblioteca, também vêm explorando os dispositivos para favorecer a participação ativa dos usuários na troca de informações, debates, comentários e sugestões. Por outro lado, identificou-se uma nova postura de comunicação adotada pelos bibliotecários nos dispositivos de comunicação na web, com uma abordagem mais amigável, cordial e acolhedora para com os usuários, tanto no momento das interlocuções quanto na disponibilização de conteúdos.

\section{REVISÃO DE LITERATURA}

As bibliotecas universitárias apresentam-se como espaço de informação e cultura, caracterizando-se como um elo entre o conhecimento que foi produzido no passado e a necessidade de crescimento dos sujeitos no presente. Por meio de materiais informacionais, que também podem ser entendidos como dispositivos culturais, uma vez que representam uma trajetória de construção histórica dos sujeitos. Nesse sentido, “[...] um dispositivo é uma instância, um lugar social de interação e de cooperação com intenções, funcionamento e modos de interação próprios." (PERAYA, 2002). Portanto, para Peraya, os dispositivos articulam três níveis de interação: a semiótica, a social e a técnica. 0 chamado dispositivo técnicosemio-pragmático (TSP) pode ser definido como o conjunto de interações entre esses três universos.

$\mathrm{Na}$ área da informação, Pieruccini (2007), ao tratar sobre dispositivo afirma que, de modo abrangente, entende-se por dispositivo de informação,

[...] signo, mecanismo de intervenção sobre o real, que atua por meio de formas de organização estruturada, utilizando-se de recursos materiais, tecnológicos, simbólicos e relacionais, que atingem os comportamentos e condutas afetivas, cognitivas e comunicativas dos indivíduos.

Dessa maneira, as bibliotecas podem ser entendidas como dispositivos que abrigam relações entre sujeitos em constante troca de informações e crescimento social e cognitivo, que também possuem e desenvolvem uma lógica própria de organização, potencializada pelas tecnologias.

Por meio desses dispositivos os usuários da informação podem interagir com outros sujeitos produtores de conhecimento no passado ou no presente, deste modo podem acessar os conteúdos informacionais, desenvolvendo e criando novas informações e conhecimentos. Latour (2000, p. 26) reflete que,

A coleção, o gabinete, o livro ilustrado, o relato, a biblioteca, servem, ao contrário, de intérprete, de intermediário, de encruzilhada, de distribuidor, de central telefônica, de dispatcher, a fim de regular as relações múltiplas entre o trabalho de redução 
e o trabalho de amplificação. Todos esses lugares estão repletos de ligações com o mundo, e cada página puxa atrás de si tantas tomadas e fichas quanto a parte posterior de um computador.

Vale ainda ressaltar que, o espaço físico das bibliotecas também representa um importante dispositivo para o desenvolvimento dos usuários da informação, haja vista que o conjunto de dispositivos materiais tem um objetivo específico que é o de possibilitar e facilitar a ambiência informacional, onde de modo confortável ocorre o acesso, uso e a apropriação da informação.

Pode-se dizer que o próprio espaço físico da biblioteca é considerado um dispositivo de mediação, podendo ser considerado uma "midiasfera", que segundo Debray (1995, p. 42) representa "[...] uma relação mental ao espaço e tempo físico. Por exemplo, não [nos] comunicamos com Deus em qualquer lugar, mas pela mediação conjugada de certos locais privilegiados com certo meio de deslocamento (santuário e peregrinações)." Assim, analisando a biblioteca na perspectiva dos estudos da midiologia realizados por Debray (1995), pode-se dizer que ela também se caracteriza como uma midiasfera, por ser um ambiente que reúne informações e promove o encontro delas com os sujeitos, por meio de ações de mediação direta ou indireta, concretizadas por um processo contínuo de interação entre os sujeitos e os materiais informacionais.

Tomando-se como referência o conceito de transmissão de Debray (1995), pode-se identificar uma equivalência entre esse conceito na esfera dos estudos da midiologia e o conceito de transferência da informação para a Ciência da Informação. Para Debray (1995, p. 62) a transmissão é “[...] um processo histórico, temporalidade lenta que não é externa, mas constitutiva do fenômeno, seu motor é razão de ser (transmitimos para anular o tempo, remontar a entropia, opor-lhe, pelo menos, uma 'ilhota de entropia decrescente')." Assim, pode-se considerar que a transmissão aproxima-se do que, no contexto da Ciência da Informação, considera-se transferência da informação, ou seja, comunicação do conhecimento registrado e organizado que ultrapassa o tempo e o espaço, possibilitando a interação entre sujeitos e potencializando o desenvolvimento de novos conhecimentos.

Frohmann (2008, p.29), apresenta um exemplo sobre a documentação de categorias de transtornos a partir do trabalho de Louis Charland, para destacar a relevância da materialidade da informação. Os efeitos da remoção de certas categorias do Manual do Diagnostico dos Transtornos Mentais (DSM), elaborado por Charland. Pacientes diagnosticados com uma das categorias removidas, a categoria do Transtorno de Múltiplas Personalidades, se organizaram para resistir ao desaparecimento dessa categoria que definia sua identidade. Quando removida a categoria da classificação dos transtornos mentais o enunciado que diz que uma pessoa sofre de múltipla personalidade é "desmaterializado". O desaparecimento documentário do enunciado remove-o não só de um largo escopo de práticas institucionais, mas também ameaça a existência dos pacientes num largo escopo de práticas individuais, sociais e culturais.

Nessa perspectiva, o autor ainda afirma que, "[...] não pode haver informação sobre algo de um tipo X se este tipo não existir. E se o tipo não pode existir sem documentação, então a documentação é necessária para que 
haja informação sobre ele." (FROHMANN, 2008, p. 28). Esse pensamento de Frohmann converge com o pensamento de Debray (1993) quando este afirmar que,

\begin{abstract}
No homem, o utensílio prolonga o gesto e se desliga dele. Este desligamento, ou esta exteriorização material das faculdades humanas, 'produzidas' de certo modo pelo corpo e pondo-se a viver uma vida autônoma em uma sucessão de utensílios e máquinas, define, tanto a linguagem, o critério de humanidade. Meu cérebro há de morrer, mas não estas notas que decifro diante de vocês, inscritas com tinta sobre um papel que vai durar mais do que eu. [...] 0 utensílio sobrevive ao órgão. (DEBRAY, 1993, p. 81).
\end{abstract}

A documentação pode ser entendida como um dispositivo que proporciona a transferência da informação sobre algo ou sobre alguém independente do contato direto com seu autor. Embora as descobertas e conhecimentos produzidos possam ser compartilhados por meio da comunicação direta, em reuniões e eventos científicos apenas por via do registro, da documentação, as informações serão transferidas e compartilhadas com pares distantes geograficamente ou com as gerações futuras. 0 processo da documentação amplia a quantidade de sujeitos que poderá ter acesso a informação registrada, quebrando as barreiras tanto temporais quanto geográficas.

A web social potencializa a colaboração e interação entre os sujeitos, rompendo com as barreiras sociais, geográficas e temporais. Ao conceituar a web social Blattmann e Silva (2007) afirmam que esta é: "A construção de espaços para colaboração, interação e participação comunitária tem sido chamado de Web 2.0." Por meio dos dispositivos de comunicação criados e disponibilizados na web, os sujeitos podem compartilhar informações, atraindo indivíduos que possuam necessidades e características comuns, formando rede de contato pessoal, acadêmico e profissional.

Nesse sentido, ao criar um espaço virtual, utilizando recursos de comunicação da web social, a biblioteca poderá promover a participação e atuação dos usuários, seja na construção e disponibilização de textos ou no debate de informações com outros usuários. A “[...] Web 2.0 é um novo espaço para acessar, organizar, gerenciar, tratar e disseminar a informação, conhecimentos e saberes. [...] cabe estudar, experimentar, explorar tecnologias da Web 2.0 para facilitar o acesso e ampliar o uso da informação." (BLATTMANN; SILVA, 2007).

Os dispositivos de comunicação da web social disponibilizados pelas bibliotecas universitárias são entendidos, nessa pesquisa, como dispositivos que podem favorecer as ações mediadoras de informações, tornando mais dinâmica a comunicação entre os usuários que compõem as redes sociais. Para Almeida Júnior a mediação da informação pode se dar de duas maneiras: implícita e explicitamente. Essa categorização das atividades de mediação toma como referência a conceituação apresentada por Almeida Junior (2008), para quem a mediação da informação é,

[...] toda ação de interferência-realizada pelo profissional da informação-direta ou indireta; consciente ou inconsciente; singular ou plural, individual ou coletiva; que propicia a 
apropriação de informação que satisfaça, plena ou parcialmente, uma necessidade informacional.

A mediação implícita está presente nas atividades meio da biblioteca, como por exemplo, a seleção, aquisição, registro, catalogação, classificação, indexação, nas quais não há a presença do usuário, mas há a intenção de atender suas necessidades informacionais e a preocupação em fornecer formas de apoio a esses usuários na identificação e localização da informação. Logo a mediação explícita está relacionada às atividades fins, como as de disseminação seletiva da informação e do serviço de referência, nas quais há um alto grau de interlocução direta entre usuários e bibliotecários.

Freitas (2009), ao refletir sobre as novas dinâmicas decorrentes da utilização do computador e da internet, afirma que esses,

[...] introduzem uma forma de interação com as informações, com o conhecimento e com as outras pessoas, totalmente nova, diferente da que acontece em outros meios como a máquina de escrever e o retroprojetor. [...] Computador e internet abrem novas possibilidades de aprendizagem por permitirem o acesso a uma infinidade de informações, [...] Portanto, eles possibilitam a construção compartilhada de conhecimento, via interatividade, de que fala a teoria histórico-cultural.

A web social, enquanto dispositivo que possibilita a interação entre os sujeitos, pode ser compreendida, a partir da concepção de Vygotsky, como um instrumento que atua no ambiente cultural e social ao favorecer comunicação e cooperação entre os sujeitos, na troca de informações, além, de nessa relação, possibilitar a ação de outro sujeito o mediador da informação. Como afirma Freitas (2009) esse dispositivo oferece suporte para a interação com as informações e com "outras pessoas". Utilizar os dispositivos de comunicação da web social para potencializar as atividades mediadoras das bibliotecas torna-se fundamental, pois, estes já estão incorporados ao cotidiano de grande parte dos indivíduos, transformando suas formas de interação social.

Identifica-se por meio de estudos nacionais e internacionais a adoção, e em certa medida um avanço, na utilização dos dispositivos de comunicação da web social pelas bibliotecas universitárias. Entre os estudos sobre os dispositivos de comunicação da web social, no contexto das bibliotecas universitárias, pode ser citado o estudo sobre a utilização dos dispositivos de comunicação da web social, como Facebook, Orkut, Myspace e Ning, pelas bibliotecas universitárias, entre essas bibliotecas universitárias do Brasil, Estados Unidos e Espanha, realizado por Aguiar e Silva, em 2010; que também investigaram as informações disponibilizadas e o tipo de interação que é estabelecida com os usuários. Os autores identificaram que grande parte das bibliotecas universitárias pesquisadas apesar de utilizarem os dispositivos de comunicação da web social (Facebook, Orkut, Myspace e Ning), ainda não fazia uso de modo interativo e participativo, o que ainda requer certa melhoria. "A maioria somente as utilizam como um canal de comunicação de via única, ou seja, não se utilizam dos recursos interativos (fórum, enquetes, etc.), uma das principais características da Web 2.0" (AGUIAR; SILVA, 2010). 
Aguiar e Silva (2010) consideraram a necessidade das bibliotecas universitárias usarem as potencialidades dos dispositivos de comunicação da web social, tornando-os mais atrativos, além de divulgarem esses dispositivos de comunicação de modo mais intenso entre os usuários, para que esses possam ter conhecimento da existência desses dispositivos e passar a utilizálos. Os autores (2010) ainda afirmaram a importância dos bibliotecários responsáveis pelos dispositivos conhecerem os princípios e fundamentos que norteiam as redes sociais para uma utilização mais consciente dos seus recursos.

Grande-González e De-la-Fuente-Redond, também realizaram, em 2012, um estudo sobre a utilização dos dispositivos de comunicação da web social, no contexto das bibliotecas universitárias espanholas. Entre os resultados de suas investigações, os autores constataram que todos os bibliotecários pesquisados (29) consideram importante a biblioteca universitária incorporar as aplicações web social em seu website, entretanto apenas 34,5\% (10 de 29), apresentam uma política de uso para os recursos de comunicação da web social. Contudo, segundo Grande-González e De-laFuente-Redondo (2012) foi observado que existe uma tendência das bibliotecas em desenvolver um plano estratégico voltado ao uso dos dispositivos de comunicação da web social.

Baro, Idiodi e Godfrey (2013) também investigaram a utilização dos dispositivos de comunicação da web social entre os bibliotecários nas bibliotecas universitárias na Nigéria. Entre os resultados, foi identificada uma tendência das bibliotecas universitárias na Nigéria adotarem o Facebook, sendo o dispositivo que mais vem sendo utilizado por essas bibliotecas, seguido do Twitter. Esse estudo também revelou que as bibliotecas universitárias na Nigéria utilizam os dispositivos de comunicação da web social principalmente para serviços de referência on-line, notícias, especialmente sobre eventos da biblioteca, como recursos para a formação dos usuários e o compartilhamento de imagens e vídeos. A partir desse dado e da tendência dessas bibliotecas universitárias adotarem o Facebook e o Twitter, infere-se que essas bibliotecas têm como objetivo, por meio do uso dos dispositivos de comunicação da web social, aproximar-se dos usuários e especialmente apoiar o desenvolvimento desses sujeitos por meio das atividades de mediação direta da informação.

Observa-se que os dispositivos de comunicação na web social disponibilizados pelas bibliotecas universitárias podem favorecer a interação entre a biblioteca e a comunidade acadêmica e entre os integrantes dessa comunidade. É nesse contexto de utilização do espaço virtual para ação comunicativa e interação, que a biblioteca universitária deve buscar ampliar a mediação da informação. A web social permite uma ação mais intensa de comunicação entre bibliotecários e usuários, portanto, deve ser estuda e explorada.

\section{A TRAJETÓRIA METODOLÓGICA}

A pesquisa desenvolvida no curso de Mestrado em Ciência da Informação teve por objetivo identificar e analisar como as bibliotecas das universidades federais e estaduais têm explorado os recursos de comunicação nos websites 
para ampliar suas ações voltadas à mediação para o acesso e uso da informação. Por se tratar de um universo de grandes proporções trabalhouse com uma amostra composta pelas bibliotecas centrais e/ou sistemas de bibliotecas dessas universidades já que, em princípio, desenvolvem liderança na adoção e experimentação de novas ferramentas.

$\mathrm{Na}$ análise dos websites das bibliotecas centrais e/ou sistemas de bibliotecas das IES Estaduais e das IFES foram identificadas 91 bibliotecas centrais e/ou sistemas que utilizam algum tipo de dispositivo para o estabelecimento da comunicação entre bibliotecários e usuários, como também os tipos de dispositivos de comunicação utilizados por elas, o tipo de interlocução que ocorria com maior frequência e de que maneira os bibliotecários costumavam formular suas respostas. Nesse trabalho foram apresentados e discutidos uma parte dos resultados da pesquisa de mestrado, em que se buscou avaliar as possibilidades de utilização dos dispositivos de comunicação da web social pelas bibliotecas universitárias, bem como a dialogia entre bibliotecários e usuários.

Por meio das observações realizadas foi possível identificar ações realizadas por uma quantidade de bibliotecas universitárias, como: disponibilização de conteúdos de interesse dos usuários, independente do suporte, divulgação de atividades e eventos, interlocuções realizadas no dispositivo de comunicação em torno de questões relacionadas ao acervo da biblioteca, entre outras ações de mediação da informação, voltadas ao acesso, uso e apropriação da informação.

\section{APRESENTAÇÃO E DISCUSSÃO DOS RESULTADOS}

Como resultado da oferta de dispositivos de comunicação das 129 bibliotecas centrais e/ou sistemas de bibliotecas que oferecem diversas informações em seus sites, 91 delas disponibilizam algum tipo de dispositivo que permite uma interação direta com seus usuários. Desses 91 sites, 39 deles (42,9\%) pertencem às bibliotecas centrais e/ou sistemas de bibliotecas das IFES e $52(57,1 \%)$ pertencem às bibliotecas centrais e sistemas de bibliotecas das IES Estaduais. Ao examinar o uso dos dispositivos de comunicação da web social pelas bibliotecas centrais e sistemas de bibliotecas das IES, se percebe certo avanço em relação às pesquisas anteriores, já que dos 91 sites de bibliotecas examinados que possuem algum tipo de dispositivo de comunicação (IFES - 39 / IES Estaduais - 52) realizam um total de 103 ofertas de dispositivos de comunicação da web social.

Ainda verificou-se que das 45 ofertas de dispositivos da web social nos sites das bibliotecas das IFES, a maior parte delas corresponde ao twitter (18 - 40,0\%), ao facebook (10 - 22,2\%) e ao blog (8 - 17,8\%), resultados semelhantes aos obtidos junto às bibliotecas das IES Estaduais, onde 22 ofertas dizem respeito ao twitter (37,9\%), 16 ao blog $(27,6 \%)$ e 7 ao facebook $(12,1 \%)$. Apesar de existir uma inversão quanto ao lugar ocupado pelo blog e facebook nas bibliotecas das IES Estaduais (facebook - 12,1\% - blog - 27,6\%) e das IFES (blog- 17,8\% - facebook - 22,2\%), observa-se que depois do twitter, esses dispositivos são os que mais se destacam quanto à utilização pelas bibliotecas centrais e/ou sistemas de bibliotecas das universidades 
públicas brasileiras, resultado que se aproxima do identificado por Baro, Idiodi e Godfrey (2013), no contexto das bibliotecas universitárias na Nigéria.

No percurso em que o sujeito desenvolve para se apropriar da informação e produzir novos conhecimentos, o acesso e o uso a informações de confiabilidade devem ser priorizados, principalmente em um ambiente como o da web, onde ainda é precário o processo de identificação e localização da informação de maior grau de confiabilidade. Nesse sentido, como um ambiente que trabalha com a informação e o bibliotecário, como um profissional que está apto a organizar, tratar, gerir, avaliar e disponibilizar informações que tenham credibilidade cientifica, a biblioteca universitária deve estar atenta para a realização de atividades que apoiem o usuário na identificação de informações de qualidade.

Quanto a isso se pode afirmar que as bibliotecas centrais e/ou sistemas de bibliotecas das universidades estaduais e federais disponibilizam links de acesso a revistas científicas, livros digitais, vídeos, teses e dissertações, artigos científicos, entrevistas de especialistas, enfim, publicações diversas da web (IES Estaduais -1063 / IFES - 562), favorecendo em alguma medida que os usuários tenham acesso às informações relevantes que poderão contribuir para sua formação acadêmica, além de utilizar formas diversificadas de documentos, adotando a que tiver maior facilidade e afeição.

Os usuários não apenas possuem necessidades de informação relacionadas a um conteúdo, mas também precisam ser introduzidos nas práticas acadêmicas de debate das experiências e informações. Nessa perspectiva, é relevante que os usuários também sejam incentivados a participar de eventos relacionados ao seu campo do conhecimento para que também possam interagir com outros sujeitos que refletem sobre a temática de seu interesse. Esse é um aspecto que parece estar sendo observado pelas bibliotecas já que quanto à divulgação de atividades e eventos é um dos conteúdos que mais se destaca em apresentação nos dispositivos de comunicação das bibliotecas (IES Estaduais - 2125/ IFES - 614). As bibliotecas que disponibilizam informações sobre eventos, tanto divulgam aqueles da área do conhecimento dos usuários quanto outros eventos realizados pela própria biblioteca e que podem auxiliá-los no desenvolvimento de competências e potencializando a formação de um sujeito autônomo. Vale destacar que uma parcela considerável de bibliotecas centrais e/ou sistemas de bibliotecas das universidades estaduais e federais vêm orientando e estimulando os usuários a participarem dessas atividades. Entretanto, como se trata de bibliotecas que são referência para as demais bibliotecas, seria importante que aquelas que ainda não assumiram a responsabilidade de realizar a divulgação dos eventos e realização de atividades do gênero passem a oferecer esse serviço aos seus usuários, de modo que eles tenham informações a respeito e se sintam incentivados a participar dos eventos acadêmicos e científicos, como também de atividades desse tipo organizadas pelas bibliotecas.

As informações sobre o acesso ao acervo da biblioteca, ou mais especificamente as interlocuções realizadas no dispositivo de comunicação em torno de questões relacionadas ao acervo auxiliam os usuários na recuperação das informações que necessitam, isso pode verificado no 
seguinte exemplo: "me pergunto em que parte da @bibfauusp vou achar o trabalho de Marcelo Barbosa sobre o Franz Heep ...". A partir dessa pergunta o representante da biblioteca indicou exatamente a posição desse material na estante, facilitando o acesso a informação para o usuário, e de outros com as mesmas dificuldades que venham a ler a resposta que informou: "Aqui: 724.981 H36o (bibl. graduação) ou aqui 043:72.036 B238o (bibl. pósgraduação) 'A obra de Adolf Franz Heep no Brasil'." Ao indicar o modo pelo qual o usuário poderá recuperar a informação de que precisa, informando a localização do livro na estante, a biblioteca realiza no ambiente web, atividades de mediação da informação semelhantes àquelas tradicionalmente desenvolvidas no setor de referência, onde o usuário tem o auxilio do bibliotecário para ter acesso a informação. A diferença agora é que, ao fazer isso por meio de um dispositivo de comunicação na web, essa orientação pontual pode alcançar outros usuários que visitam o ambiente do dispositivo.

Além das interlocuções sobre o acesso ao acervo, também foram disponibilizados conteúdos que informavam e divulgavam o próprio acervo das bibliotecas centrais e/ou sistemas de bibliotecas das IES Estaduais e das IFES, totalizando 114 conteúdos disponibilizados pelas bibliotecas das IES Estaduais e apenas 38 conteúdos das bibliotecas das IFES. Ainda que não haja uma consciência clara por parte do bibliotecário que responde a esse tipo de questão, existe nesta situação uma atividade de mediação direta, já que ao responder a um questionamento sobre a característica do acervo, seus materiais e especificidades temáticas, a biblioteca está orientando e facilitando o processo de atendimento as necessidades informacionais do usuário.

Os resultados indicam que as informações e interlocuções sobre o acervo nos dispositivos da web social representam o foco mais forte e central do processo de mediação da informação, haja vista, que este é o ponto claramente motivador de interação entre bibliotecários e usuários para a solução de dúvidas referentes ao uso do acervo e sua contribuição. Entretanto, a biblioteca pode ir além da comunicação que informa questões ligadas ao acervo. Elas podem desenvolver um diálogo descontraído e objetivo no atendimento individual de cada usuário, lembrando que cada informação exposta nos dispositivos de comunicação da web social será visualizada pelos demais usuários, portanto, poderá também auxiliá-los enquanto leitores. 0 clima amigável e próximo desse tipo de orientação pode reforçar laços de cumplicidade essenciais para a mediação.

Assim, atividades de mediação da informação que antes eram realizadas apenas formalmente nos ambientes físicos das bibliotecas, podem agora ser ampliadas pela oferta de orientações nos dispositivos de comunicação da web social, o que gera maior aproximação entre a biblioteca e os usuários potenciais, pois, estes em grande medida fazem uso desses dispositivos e desse estilo de comunicação, já incorporados em seus modos de interação social.

A divulgação de conteúdos sobre temas e materiais relacionados ao campo de conhecimento da biblioteca (bibliotecas das IES Estaduais - 543/ bibliotecas das IFES - 58), como também informações sobre o ensino, pesquisa e comunicação científica (bibliotecas das IES Estaduais - 951/ bibliotecas das IFES - 258), posicionam os usuários no processo de formação, 
de ensino-aprendizagem, não como sujeitos passivos, mas proporcionam subsídios para tornarem-se críticos, reflexivos e autônomos. Ao disponibilizar links de acesso a conteúdos que abordam uma temática especifica da área do conhecimento do acervo, a biblioteca oferece aos usuários a chance de ampliar as informações que já possuem sobre um determinado tema. No entanto, vale chamar atenção que neste tipo de indicação a biblioteca não está destacando um periódico ou outro tipo de suporte que contém uma informação específica, mas está direcionando diretamente o leitor para um conteúdo disponível na internet, proporcionando, desse modo, o acesso qualificado e direto à informação, além de facilitar a busca, poupando o tempo do usuário. Portanto, a disponibilização desses conteúdos nos dispositivos de comunicação indica a possibilidade de aprendizagem para os usuários a partir da web, já que esta, como lembra Freitas (2009), permite o acesso a uma infinidade de informações que abordam as questões acerca do próprio desenvolvimento do seu campo científico.

Ao potencializar a utilização dos seus produtos e serviços, apresentar conteúdos sobre a biblioteca e bibliotecários, assim como ao estimular a própria visitação e exploração do ambiente físico da biblioteca, a exemplo de quando expõem imagens do ambiente físico, os bibliotecários estão tentando apresentar um espaço de estudo, mas precisam compreender e tratar esse local como uma midiasfera, buscando mostrá-lo ao usuário na perspectiva de Debray (1993; 1995), como um ambiente que reúne informações, instrumentos, recursos, agentes e ações que se articulam e por meio dos quais se alcança a produção de sentidos e, ao mesmo tempo, a transmissão de saberes.

Conduzindo o trabalho nessa dimensão, a biblioteca permite que o usuário reconheça a importância que a biblioteca tem para a sua formação acadêmica, e tenderá a compreender mais claramente o significado e o potencial desse ambiente como importante ponto de apoio na prática da pesquisa e produção científica. Enfim, os usuários passarão a entender a biblioteca na perspectiva destacada por Latour (2000) quando ele, ao descrever o ambiente físico da biblioteca, afirma que é nele que os leitores escrevem, pensam e se relacionam com o mundo.

Tomando-se como referência essa reflexão de Latour (2000), torna-se necessário que as bibliotecas ampliem ações que mais diretamente promovam discussões que proporcionem aos usuários uma compreensão mais profunda sobre a relevância do ambiente da biblioteca, do papel do bibliotecário, e dos elementos materiais e imateriais que estão disponíveis na biblioteca, e que podem vir a gerar benefícios sociais, culturais e cognitivos. Embora pouco significativa, a quantidade de conteúdos acerca da biblioteca como ambiente de cultura e conhecimento, (IES Estaduais - 71/ IFES - 18), sobre o profissional bibliotecário (IES Estaduais - 48/ IFES - 17) e sobre o livro (IES Estaduais - 175/ IFES - 25), divulgados especialmente pelas bibliotecas centrais e/ou sistemas de bibliotecas das IFES, percebe-se a existência de uma intenção dessas bibliotecas em divulgar e apresentar uma reflexão sobre esses elementos, abrindo um espaço de interlocução para que seus usuários se manifestem a respeito. No entanto, é necessário que essa iniciativa se fortaleça e ampliando-se a quantidade de conteúdos e debates 
sobre atividades, ações, papel e missão da biblioteca, como aspecto também indicado por Aguiar e Silva (2010) em sua pesquisa, considerando a necessidade das bibliotecas universitárias usarem as potencialidades dos dispositivos de comunicação da web social, tornando-as mais atrativas.

O bibliotecário, mediador cultural por trabalhar diretamente com objetos culturais como o livro, deve ter consciência sobre a sua responsabilidade em aproximá-los dos usuários ou dos grupos de usuários, como defendem Cunha e Cavalcanti (2008). Como mediador cultural, o bibliotecário deve proporcionar condições para que os usuários das bibliotecas universitárias acessem a informação científica e, ao mesmo tempo, passem a compreender a função da comunicação científica e dos suportes de registro dessa informação.

A biblioteca universitária também tem a missão de favorecer a compreensão dos usuários sobre a relevância de se produzir e registrar o conhecimento científico para o compartilhamento, mas também para as gerações futuras. 0 usuário da biblioteca universitária precisa compreender a lógica da transferência da informação, como ação que permite por meio do registro da informação em determinado suporte, que o sujeito prolongue o acesso às suas experiências, descobertas e experimentações para além do tempo e do espaço, possibilitando que sejam examinadas e discutidas por outros sujeitos. (DEBRAY, 1993; FROHMANN, 2008). Enfim, a biblioteca deve apoiar os usuários na reflexão sobre a importância do registro e comunicação científica, que permitem a materialidade da informação, necessária à memória e desenvolvimento da ciência.

Nessa mesma perspectiva, a biblioteca universitária deve trabalhar no sentido de favorecer que seu usuário perceba que no acesso à informação científica ele não pode ficar restrito ao uso de uma única biblioteca. Além disso, devem apresentar informações sobre a instituição universidade, contribuindo para que seus usuários, em especial os estudantes, ampliem a compreensão sobre a dinâmica dos espaços que atuam na formação acadêmica, no desenvolvimento e acesso ao conhecimento científico. Assim, neste trabalho observou-se que as bibliotecas centrais e/ou sistemas de bibliotecas também disponibilizavam conteúdos sobre a universidade a qual estão vinculadas (IES Estaduais - 214/ IFES - 72), ou ainda informações e relatos de experiências sobre outras bibliotecas e unidades de informações, a exemplo de museus e arquivos, sendo que as bibliotecas das IES Estaduais têm trabalhado mais esses conteúdos, já que apresentaram 263 conteúdos, enquanto as bibliotecas das IFES apresentaram apenas 87 conteúdos desse tipo. Além de oferecer informações relacionadas ao ambiente físico de outras unidades de informação e instituições, e sobre as atividades que elas desenvolvem, essas bibliotecas também indicam o acesso a dispositivos de comunicação dessas instituições na web (IES Estaduais 142 conteúdos / IFES - 59 conteúdos).

Esse resultado demonstra que as bibliotecas centrais e/ou sistemas de bibliotecas das IFES, mas em especial as das IES Estaduais estão preocupadas em indicar as possibilidades dos usuários em relação à busca e ao acesso a informação para além dos seus serviços, ampliando o universo de acesso e uso da informação. Ao apresentar alternativas de ambientes para acesso à informação como outras bibliotecas, arquivos, museus e até mesmo os 
espaços virtuais dessas unidades de informação, a biblioteca conduz os usuários a refletirem sobre outras possibilidades de localização, o que pode favorecer o desenvolvimento de sujeitos mais autônomos na busca da informação.

\section{CONSIDERAÇÕES FINAIS}

A análise dos resultados desta pesquisa sinaliza alguma evolução no uso dos espaços virtuais pelas bibliotecas centrais e/ ou sistemas de bibliotecas das universidades brasileiras, especialmente na iniciativa em adotar os dispositivos de comunicação para disponibilizar informações e para aproximação entre bibliotecários e usuários, como também na ressignificação das atividades de mediação dessas bibliotecas e da imagem de ambiente de informação e seus profissionais.

$\mathrm{Na}$ perspectiva da disponibilização dos conteúdos, os resultados obtidos nessa pesquisa apontam que uma quantidade significativa das bibliotecas vem realizando atualização constante dos conteúdos nos

dispositivos de comunicação. Esse resultado sinaliza uma preocupação dos bibliotecários em manter os usuários informados.

Por meio da trajetória investigativa nos dispositivos de comunicação das bibliotecas centrais e/ou sistemas de bibliotecas foi possível verificar e confirmar que a utilização desses dispositivos está mais direcionada à apresentação de conteúdos que tratam sobre a área do conhecimento relacionada ao acervo da biblioteca. Mesmo que essa ação seja importante para se manter os usuários atualizados quanto às informações disponíveis sobre suas áreas de estudo, como também a oferta de notícias sobre a biblioteca, é necessária a exploração desses espaços para a realização de debates, estimulando os comentários sobre esses conteúdos, enfim a realização de ações que estimulem a participação mais ativa dos usuários. É necessário ampliar as possibilidades de uso desses dispositivos, não apenas para acesso a informações, mas para desenvolver colaboração e interação entre os sujeitos.

Com a realização desta pesquisa também foi possível constatar que as interlocuções ocorreram em uma quantidade pequena de dispositivos das bibliotecas, o que aponta que mesmo o número de interlocuções sendo significativo, essas foram potencializadas por um grupo menor de bibliotecas. Resultado que indica a necessidade de que as bibliotecas e seus representantes passem a refletir sobre a maneira pela qual estão utilizando os dispositivos de comunicação, assim como a tornarem uma ação constante a análise sistemática de como se desenvolve o processo de comunicação nos seus dispositivos e naqueles de outras bibliotecas, a fim de identificar possibilidades de enriquecimento de suas atividades.

\section{REFERÊNCIAS}

AGUIAR, Giseli Adornato de; SILVA, José Fernando Modesto da. As bibliotecas universitárias nas redes sociais: facebook, Orkut, myspace e ning. 
In: SEMINÁRIO NACIONAL DE BIBLIOTECAS UNIVERSITÁRIAS , 16., 2010, Rio de Janeiro. Anais eletrônicos... Rio de Janeiro: Universidade Federal do Rio de Janeiro. Disponível em:

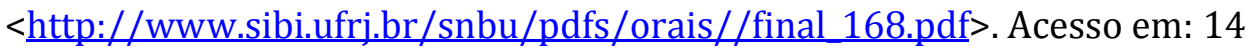
mar. 2010.

ALMEIDA JÚNIOR, Oswaldo Francisco de. Mediação da Informação e Múltiplas Linguagens. In: ENCONTRO NACIONAL DE PESQUISA EM CIÊNCIA DA INFORMAÇÃO, 9., 2008, São Paulo. Anais... São Paulo: Universidade de São Paulo, 2008. 1 CD-ROM.

BARO, Emmanuel E.; IDIODI, Evelyn O.; GODFREY Vera Zaccheaus. Awareness and use of Web 2.0 tools by librarians in university libraries in Nigeria. Library Hi Tech News, v. 30 n. 5, p. 10-20, 2013.

BLATTMANN, Ursula; SILVA, Fabiano Couto Corrêa da. Colaboração e interação na web 2.0 e biblioteca 2.0. Revista ACB: Biblioteconomia em Santa Catarina, Florianópolis, v. 12, n. 2, 2007. Disponível em:<http://revista.acbsc.org.br/index.php/racb/article/view/530/664> Acesso em: 20 set. 2009.

CUNHA, Murilo Bastos; CAVALCANTI, Cordélia Robalinho de Oliveira. Dicionário de Biblioteconomia e Arquivologia. Brasília: Briquet de Lemos, 2008.

DEBRAY, Régis. Curso de midiologia geral. Petrópolis, RJ: Vozes, 1993. LATOUR, Bruno. Redes que a razão desconhece: laboratórios, bibliotecas, coleções. In: BARATIN, Marc; JACOB, Christian (Coord.). 0 poder das bibliotecas: a memória dos livros no ocidente. Rio de Janeiro: UFRJ, 2000.

DEBRAY, Régis. Manifestos midilógicos. Petrópolis, RJ: Vozes, 1995.

FREITAS, Maria Teresa de Assunção. Janelas sobre a utopia: computador e internet a partir do olhar da abordagem histórico-cultural. In: REUNIÃO ANUAL DA ASSOCIAÇÃO NACIONAL DE PÓS-GRADUAÇÃO E PESQUISA EM EDUCAÇÃO, 32., 2009, Caxambu. Anais eletrônicos... Caxambu : Anped, 2009. Disponível em:

<http://www.anped.org.br/reunioes/32ra/arquivos/trabalhos/GT16-5857-Int.pdf> Acesso em: 22 nov. 2010.

FROHMANN, Bernard. 0 caráter social, material e público da informação. In: FUJITA, Spotti Lopes; MARTELETO, Regina Maria; LARA, Marilda Lopes Ginez de. (Orgs.). A dimensão epistemológica da Ciência da Informação. Marília: Cultura Acadêmica, 2008. p. 19-34.

GRANDE-GONZÁLEZ, Pilar; DE-LA-FUENTE-REDONDO, Pablo. Bibliotecas universitarias españolas en la web social. El Professional de la Información, Barcelona, v. 21, n. 6, p. 577-584. 2012. Disponível em: <http://dx.doi.org/10.3145/epi.2012.nov.04> Acesso em: 14 set. 2014. 
PERAYA, Daniel. 0 ciberespaço: um dispositivo de comunicação e de formação midiatizada. In: ALAVA, S et al. Ciberespaço e formações abertas: rumo a novas práticas educacionais? Porto Alegre: Artmed, 2002.

PIERUCCINI, Ivete. Ordem informacional dialógica: mediação como apropriação da informação. In: ENCONTRO NACIONAL DE PESQUISA EM CIÊNCIA DA INFORMAÇÃO, 8., 2007, Salvador. Anais... Salvador: Universidade Federal da Bahia, 2007. 1 CD-ROM.

VYGOTSKY, L. A formação social da mente: o desenvolvimento dos processos psicológicos superiores. 6. ed. São Paulo: Martins Fontes, 2000.

Editor do artigo: Adilson Luiz Pinto 